\title{
Checkliste zum Mind-Set
}

1. Die andere Seite ist immer Partner, niemals Feind: „Never create an enemy“ (Kohlrieser).

2. Reagieren Sie niemals auf Provokationen, stellen Sie Distanz zum Verhandlungsgeschehen her: „Don't react: Go to the balcony“ (Ury).

Beachten Sie: „If you can't control yourself, you can't control the situation“ (Goergen).

Taktiken: Time-Out oder Schweigen.

3. Befassen Sie sich mit der Wirkweise der Waffen der Beeinflussung (vgl. Abschn. 4.6).

4. Regen Sie immer wieder ein Time-Out an und identifizieren Sie die Waffen der Beeinflussung, die gegen Sie eingesetzt werden.

5. Nehmen Sie sich ausreichend Zeit: "Slow everything down“ (Greenstone).

6. Sie haben immer ein Informationsdefizit, deshalb gilt: „Verzichten Sie auf die Einschätzung der Macht" (Schranner). 